\title{
Chapter 20 \\ What Measures Can Be Taken to Reduce Health Disparity?
}

\author{
Katsunori Kondo
}

\section{Introduction}

This book has considered numerous non-communicable diseases and health problems and has described the importance of the "social determinants of health" (SDH), based on the findings of research from Japan and other countries. Even in Japan, which was a country regarded as "a nation with little inequality by achieving universal health and pension coverage half a century ago," we could find health disparities.

Up until the early 1980s, Japan was trending toward reducing income inequality as measured by the Gini coefficient (a measure of inequality in the distribution of income). However, inequality began to grow thereafter, and Japan is now one of the countries among the members of the OECD that have high Gini coefficients (i.e., higher levels of inequality). Compared to an average among the 30 OECD member countries in the mid-2000s of $10.6 \%$, Japan's poverty rate (the proportion with less than $50 \%$ of the median income) is $14.9 \%$, the fourth highest after Mexico, Turkey, and the United States [1]. The unemployment rate among youth approaches $10 \%$, and, even among those who are employed, the proportion in unstable, irregular employment, including as temporary workers, has climbed to a level of one out of every three young persons. As has been presented in the preceding chapters, there is an extensive body of research corroborating the fact that ill health is prevalent

Katsunori Kondo is also the English translator for this chapter.

K. Kondo $(\bowtie)$

Professor of Social Epidemiology and Health Policy, Department of Social Preventive Medical Sciences, Center for Preventive Medical Sciences, Chiba University, Chiba, Japan

Head of Department of Gerontological Evaluation, Center for Gerontology and Social Science, National Center for Geriatrics and Gerontology, Obu City, Aichi, Japan e-mail: kkondo@chiba-u.jp

K. Kondo (ed.), Social Determinants of Health in Non-communicable Diseases, Springer Series on Epidemiology and Public Health, https://doi.org/10.1007/978-981-15-1831-7_20 
among the poor, the unemployed, and those in irregular employment. Therefore, it is likely that this issue is also relevant in Japan, despite the relatively few studies, and that health disparities do exist. Indeed, the past decade has seen the release of findings from studies of Japanese older people [2] and children [3] at the micro level, and it is becoming evident that Japan does have health disparities.

The WHO (World Health Organization) has put emphasis on problems of health inequalities, treating the issue in a 2009 resolution adopted by the World Health Assembly and urging its member states to engage with the issue. In Japan, the publicized basic goal of the National Movement of Health Promotion-Health Japan 21 (The Second Term) — to be implemented during the 10-year period from 2013 is "Extension of healthy life expectancy and reduction of health disparities" (see Appendices).

It is necessary to refer to the recommendations and other materials provided by the WHO and to begin implementing measures. Therefore, this final chapter discusses the reasoning of the WHO and others in stressing the social determinants of health, the background to this development, and its meaning. This chapter presents these matters with a focus on the actions of the WHO to consider the sorts of measures that ought to be implemented to reduce health disparities.

\section{Why Is Attention Paid to the Social Determinants of Health?}

The focus on the "social determinants of health" within the field of public health seems like a dramatic epochal shift to rival those of primary healthcare and health promotion; this shift should be examined each decade. The authors would like to confirm how the trends of the day have shifted, the background to them, and the direction of the latest trends, and they would like to use this information as the foundation for formulating new policies.

The following three background conditions or factors can be pointed out: (1) the limitations of medicine and medical technology; (2) the difficulty of modifying lifestyles; and (3) health disparities.

\subsection{Limitations of Medicine and Medical Technology}

Since the founding of the WHO, numerous essential technologies have appeared that eliminate the causes of disease at the root level, including vaccines and antibiotics against infectious diseases, as well as nutrient supplements against undernutrition and nutrient deficiencies. Because of these technologies, infant mortality and other health indicators have improved dramatically. Medical treatments and technologies, which were developed one after another, contributed greatly to eliminating many health problems. 
However, problems that cannot be solved by technology have remained. Even when the technology exists, there can be problems of access, such as when the costs are high or the places providing treatment are not located nearby. These problems can affect, for instance, people excluded from society or those of low social standing, such as the poor or those on low incomes, as well as the unemployed or irregularly employed. Some people cannot pay for insurance and become uninsured; others have insurance but give up treatment by themselves because they cannot afford the co-payments when using services; yet others are unaware of the existence of free or inexpensive systems for health examinations; still others do not avail themselves of services because of the demands of daily life; and some, finally, can only receive care of low quality [4].

If people cannot access technologies and cannot make use of them, then these will be ineffective regardless of how advanced they are. What such people need to resolve their health issues is not further advances in medical technology but rather the removal of socioeconomic factors that act as barriers to access and usage. This is why the $\mathrm{WHO}$ and $\mathrm{UN}$ pursue universal health coverage.

\subsection{The Difficulty of Modifying Lifestyles}

The importance of noncommunicable diseases and healthy aging has increased even in developing countries as control over infectious diseases has been achieved to some degree. Representative of these are lifestyle diseases caused by the accumulated effects of unhealthy living habits. It was expected that living habits could be improved by inform citizens that lifestyle could cause disease and functional decline along with aging; thus, resources were poured into health education. However, no matter how much information is communicated, it will be ineffective if it does not change behavior and if lifestyles remain the same. Because of this, techniques have been developed based on the insights of behavioral science with the aim to bring about behavioral modifications. The effects of these programs have been validated in randomized controlled trials that provide high-quality evidence. However, these trials studied a comparatively small number of cases in the short term and under ideal laboratory conditions. Therefore, the observed effects would not necessarily be obtained under ordinary implemental conditions. Long-term effects that impact ordinary life were not sufficiently demonstrated in systematic reviews [5], and neither were effects sufficiently demonstrated in systematic reviews of intervention research on groups composed of a larger number of cases [6,7]. Symbolic of this is obesity, which has only increased, rather than decreased, in spite of a redoubling of measures against it in Europe, North America, and even in Japan-measures implemented because obesity leads to innumerable diseases.

The people needed to improve their lifestyles are likely to be difficult to be influenced through a behavioral modification approach focused on communicating information and based on health education. As it is discussed in the preceding 
chapters, the social determinants of health are behind the difficulty of modifying lifestyles.

\subsection{Health Disparities}

It is now clear that undeniable health disparities, or gaps in health status between the groups created by differences in community or socioeconomic status, are observable not just among nations but also within single countries. It has become clear that there are considerable disparities even in the fundamental human right to "life," and, moreover, clear that this gap appeared to be on an expansionary trend. At that point, the WHO, which had adopted the slogan "Health for All," dealt with these disparities as issues of social justice concerning health equity in a resolution adopted at the World Health Assembly [8], and the organization urged its member states to act. Within the resolution, the WHO placed emphasis on the social determinants of health, and it also called for action in non-health sectors.

Looking at these three background factors, it is apparent that the social determinants of health have arisen as unavoidable, central issues that are the root causes of the health problems that have persisted despite efforts to combat them over the past few decades. Initiatives to deal with the social determinants of health will presumably only produce results "in a generation" [9] rather than immediately, but it is expected that they will gradually permeate throughout various fields. Greater resources were put into health education not after all the evidence had come in as to what specifically should be done or as to how effective it would be. Similarly, interest in the social determinants of health, the development of intervention policies, and the investigation of their effects will presumably be advanced little by little as attempts based on necessity build upon one another.

\section{Three Concepts Should Be Pursued}

There are at least three concepts for dealing with the social determinants of health that should be paid much attention.

\subsection{The Approach Aimed at the Root Causes Upstream}

The first concept is the notion of looking not only at the causes of problems but also at the "causes of the causes." This is an approach in which, using a river as a metaphor, to overcome health problems - which are occurring downstream-the root causes farther upstream must be dealt with. In a life course approach, measures to deal with even those health problems presenting in adulthood are formulated while 
tracing the causes of the problems back through adolescence, childhood, birth, and then further back to the parents' generation, based on the insights of life course epidemiology. Such an approach could thus be said to be an expression of this first concept. Therefore, the WHO included in its recommendations the elimination of social inequalities themselves, as these are the root causes of health inequalities.

\subsection{Environmental Interventions}

There are two methods for modification of behaviors: (1) a method in which appeals are made to the individuals who are the principals engaging in behaviors, and (2) interventions are made in the environment to make it easy to engage in behaviors favorable to health, and, as a result, the behavior of the people living there changes in a favorable way. It is "primordial prevention." [10]

Preventive medicine also has two strategies available to it: (1) high-risk strategies aimed at individuals who possess risk factors, and (2) population strategies aimed at entire population groups. It is necessary to combine these methods and strategies. For instance, smoking cessation guidance aimed at smokers is an example of an individual intervention employing a high-risk strategy, while such techniques as smoking bans in workplaces and public spaces and increased tobacco taxes are environmental interventions employing population strategies.

As the difficulty of modifying people's lifestyles has become apparent, it has become clear that it is important to combine high-risk and population strategies rather than relying on the former alone. Among population strategies, in addition to the publicizing of information about health that had already been long practiced, emphasis has also come to be placed on creating environments conducive to good health. Moreover, there are not only natural and physical environments but also a socioeconomic environment, and it is now known that this exerts a great effect on people. To give an example, within an apparently physical environment (read: "cause") of a local community containing residential areas with parks and sidewalks built nearby and a developed public transportation system that means not having to rely on cars — which would tend to increase the amount of walking - the "cause of the cause" that would not permit people to buy or rent houses in the desirable environment of that community might be problems of economic power.

As a factor behind health disparities, people of low social status tend to be placed in poor environmental conditions. As this has become clear, the importance of population strategies and that of environmental interventions have been recognized. The Health Japan 21 (The Second Term) program called for "improvement of the quality of the social environment." 


\subsection{Consideration of Health in All Policies}

The slogan of the Adelaide Statement [11] is "Health in All Policies" (HiAP). When looking for the causes of causes upstream and attempting to approach them from a life course perspective, issues can no longer be dealt with entirely within a health or medical framework.

Such things as measures to deal with child poverty, as well as education policy, are indispensable. That being so, the framers of the statement did not insist that health and medical experts are powerless to deal with health inequalities. Instead, the WHO declared that they should involve and collaborate with non-health sectors. This includes, for instance, making appeals to departments in charge of transportation policy or to city planners to reconsider policy, or to devise future plans from the perspective of increasing the amount of walking done by the people living in an area.

\section{WHO Policy Documents}

The final report of the Commission on Social Determinants of Health [8] set out three recommendations, and these were reflected in a 2009 resolution adopted at the World Health Assembly [9]. In 2010, the WHO highlighted the necessity of initiatives that go beyond the framework of health and medicine in its Adelaide Statement [11]. Meanwhile, it also produced documents [12] on what should be attempted within public health programs.

\subsection{The Three Recommendations of the Commission on Social Determinants of Health}

The first recommendation is to improve the conditions of daily life-the circumstances in which people are born, grow, live, work, and age. The second recommendation is to tackle the inequitable distribution of power, money, and resources - the structural drivers of those conditions of daily life-globally, nationally, and locally. The third recommendation is to measure and understand the problem and assess the impact of action-measure the problem, evaluate action, expand the knowledge base, develop a workforce that is trained in the social determinants of health, and raise public awareness about the social determinants of health. Health (Equity) Impact Assessments-H(E)IA (see Chap. 18) — should be conducted to predict and assess the effects of policies on health (equity). 


\subsection{Adelaide Statement}

Many of the policies that have an effect on the social determinants of health are proposed and implemented in non-health sectors. Therefore, it is necessary to have a perspective that considers HiAP. Some examples of initiatives involving partnerships with non-health sectors include those relating to: the economy and employment; public order and justice; education and early life; agriculture and food; social infrastructure, national lands, and land use planning; transportation; the environment and sustainability; housing and community services; and national lands and culture.

\subsection{Public Health Programs}

These documents concern how to approach the social determinants of health in 12 public health programs, including those dealing with alcohol and tobacco, cardiovascular disease and diabetes, and mental health [12].

Figure 20.1 [12] presents an analytical framework common to all of these programs. This framework divides factors into four levels that ultimately give rise to differential health at the individual level. Directly, differences in the healthcare that individuals receive are observed, but, prior to that, there are differences in the vulnerability of different population groups, which might, for instance, cause different risks of becoming ill when exposed to the same factor to the same degree. There are also differences in exposure to harmful social and physical environments. Even further upstream from those, there are the social factors consisting of the types of socioeconomic contexts and positions. These overlap to give rise to health disparities. Table 20.1 [12] gives examples of social determinants of health at each of these five levels. With these, one may be able to analyze individual public health issues, find the important social determinants of health at each of the five levels, and intervene there. Then it will be necessary to ask which sort of initiatives will have what magnitude of effect-and on which people. It will be necessary to evaluate the effects and to proceed while constantly improving the initiatives.

\section{Latent Possibilities in the Approach Toward the Social Determinants of Health}

In November 2011, the WHO established the World Conference on Social Determinants of Health as a high-level meeting attended by officials at the ministerial level; the conference was held in Brazil. Approaches toward the social determinants of health characterized by such things as "an approach toward the root causes upstream," "Health in All Policies," and "environmental intervention" are more 


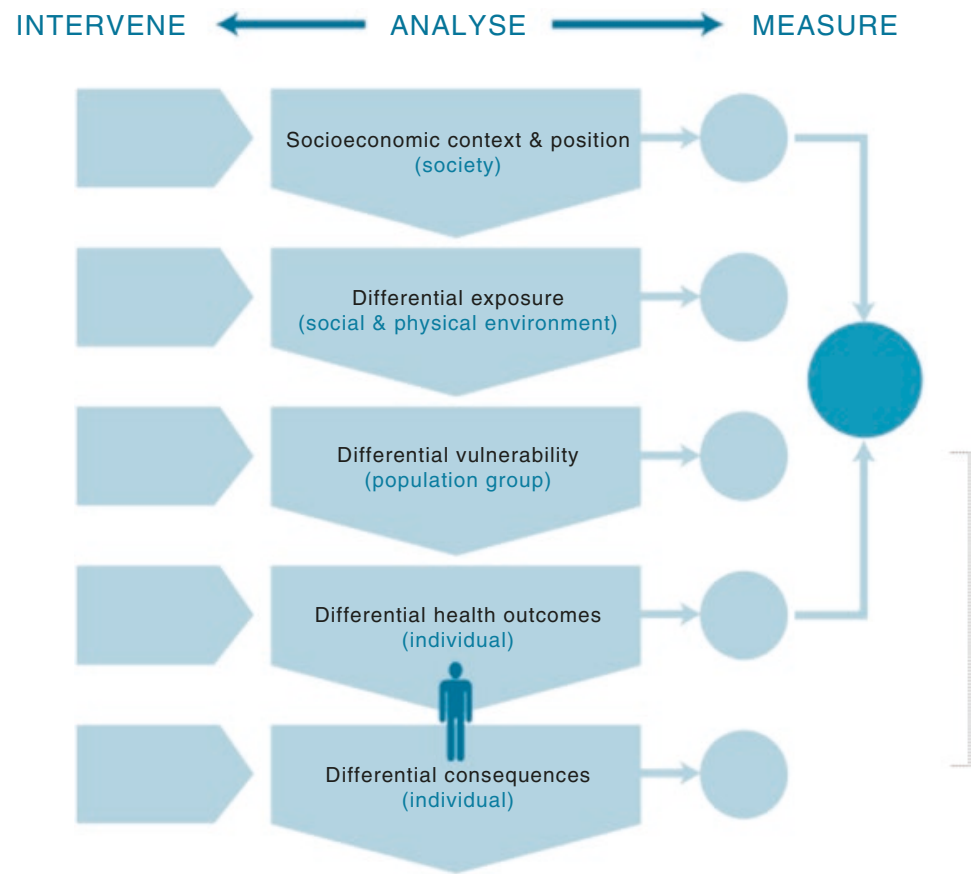

Fig. 20.1 Priority public health conditions analytical framework. (Blas E, Kurup AS: Equity, social determinants and public health programmes. World Health Organization (WHO), https:// apps.who.int/iris/bitstream/handle/10665/44289/9789241563970_eng. pdf?sequence=1\&isAllowed=y, 2010)

difficult to achieve than initiatives focused on medicine, medical technology, or lifestyle. However, the latent impact of these approaches that will be expeceted when they have developed is great. If these were to lead to continued increases in smoking cessation and physical activity, improvements of diets, reductions of psychosocial stress, or other favorable developments, then —as has been seen within the present book-one could expect effects limiting not just individual diseases but instead nearly all lifestyle diseases and stress-related conditions, as well as diseases overall.

This is similar to how improved environmental sanitation led to decreases in infectious diseases overall and thus death rates continued to decline long before technologies for treating specific diseases, such as anti-tubercular drugs, appeared. It is also similar to how, if measures to treat metabolic syndrome pay off, then high blood pressure, diabetes, and dyslipidemia will also tend to improve. Those initiatives are not exactly simple, but they will still hold great importance if undertaken.

Within Japan, developments following the WHO recommendations have begun, starting within academia. The Japanese Society of Public Health has established a working group on social inequalities and health under its monitoring and reporting committee, and it has released three reports and recommendations aimed at children, 
Table 20.1 Social determinants occurring on the pathways

\begin{tabular}{l|l}
\hline $\begin{array}{l}\text { Level of the priority public health conditions } \\
\text { framework }\end{array}$ & Major social determinants at play \\
\hline Socioeconomic context and position & Globalization and urbanization \\
Society & Social status and inequality \\
Gender & Minority situation and social exclusion \\
& Rapid demograptic change, including aging \\
population
\end{tabular}

Blas E, Kurup AS: Equity, social determinants and public health programmes. World Health Organization (WHO), https://apps.who.int/iris/bitstream/handle/10665/44289/9789241563970_ eng.pdf? sequence $=1 \&$ isAllowed $=y, 2010$

the generation in the labor force, and older people (see Appendices). The Science Council of Japan has also compiled recommendations concerning health and social inequalities through a joint public health science subcommittee of their basic medicine committee and their health and life sciences committee (see Appendices).

In dealing with health disparities, a focus on the social determinants of health and a perspective of HiAP are indispensable. These will presumably begin with actions in the health and medical sector. It will start with health and medical professionals increasing their understanding of health disparities and the importance of the social determinants of health, and they will then urge those around them to act.

Health Japan 21 (The Second Term), published in 2012, set a reduction of disparity of healthy longevity (a period without limitations in everyday life) among prefectures as its goal. Healthy longevity by prefecture for 2010 was $71.74-68.95$ years for men and 75.32-72.37 years for women, with a difference of 2.79 and 2.95 years for men and women, respectively (see Fig. 20.2). There were concerns on whether health disparities, which has its root cause in social disparities, could be reduced or 


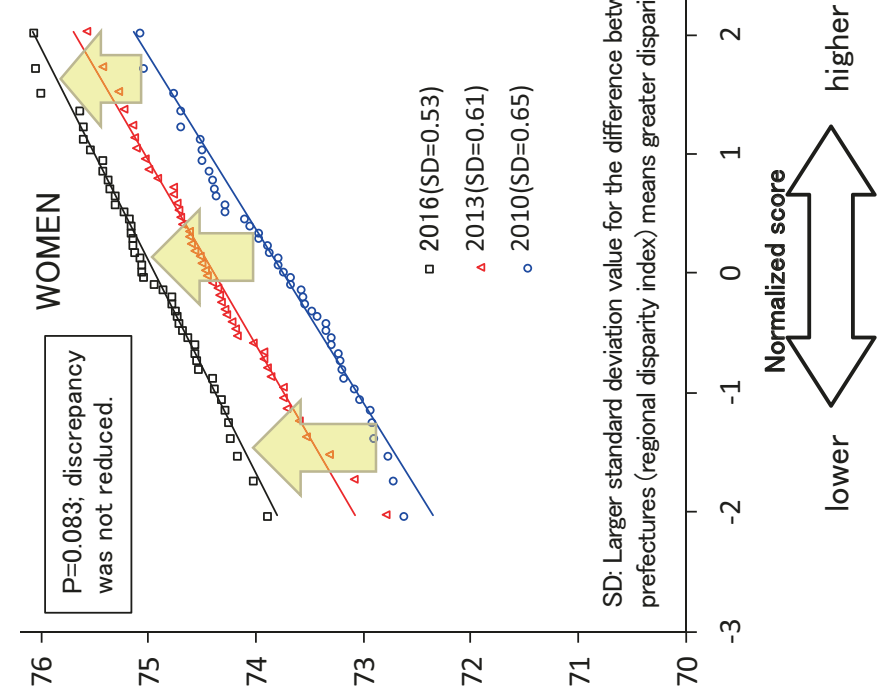

Average period without limitations in everyday life (years)

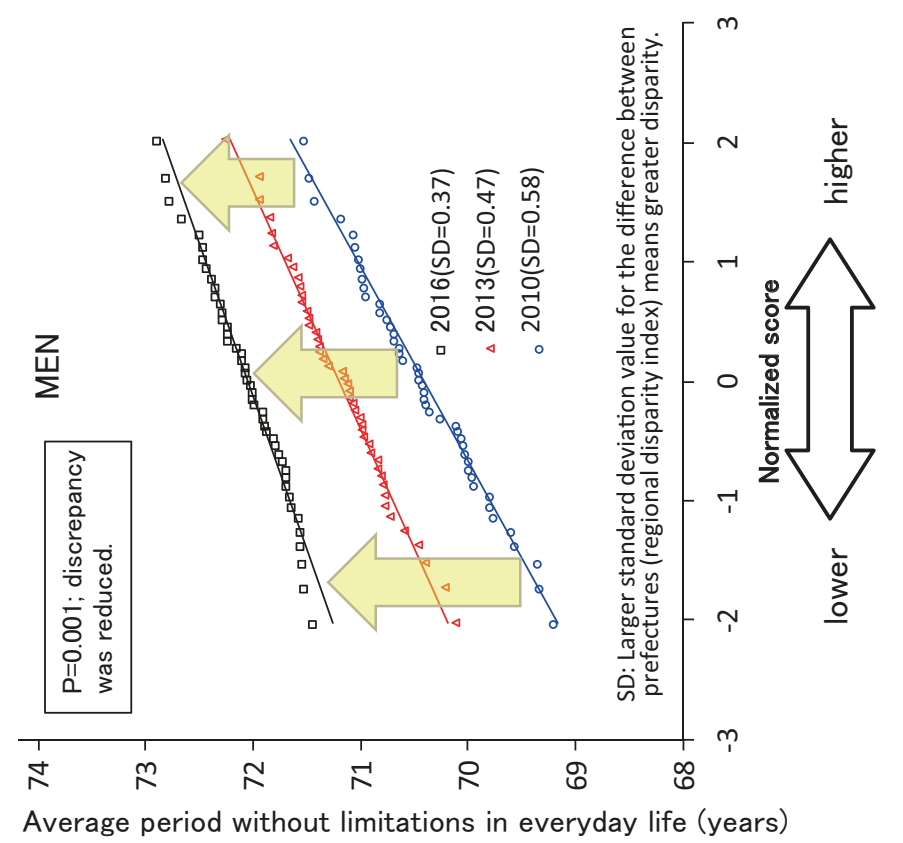

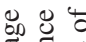

घ잉

을 요

预

$\exists \mathscr{\Xi}$

는 은

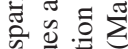

氜売 등 ᅯ ฮ류 廿ै

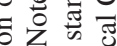
。일

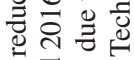
크르르 을 글 로용 造总

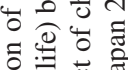
式

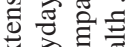

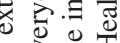
\& 己

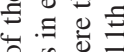
은 बํㅠ

ฮี एँ 运苛总 ง สิ่

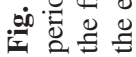


not. However, mid-term evaluation of Health Japan 21 (The Second Term) published 5 years later showed that disparities in healthy longevity by prefectures (standard deviation: SD) reduced from 0.58 to 0.37 for men and $0.65-0.53$ for women by 2016 (see Fig. 20.2).

Factors that led to this reduction are yet to be identified. Assessment of the mechanism and the size of impact of policies that are effective in reducing health disparities are expected to reduce disparities even further. Developments will occur based on unique Japanese efforts and those of other countries through trial and error. An example of such effort in Japan is the JAGES (Japan Gerontological Evaluation Study) initiative for universal health coverage and healthy aging. We described the lessons and key driving factors derived from 20 years of efforts of JAGES in a monograph [13].

Through these processes and efforts, it is expected that the goal and recommendations proposed by the WHO can be realized; that is, "Closing the gap in a generation: Health equity through action on the social determinants of health" [8].

\section{References}

1. OECD. Income distribution - poverty. Paris: OECD. Available at http://stats.oecd.org/Index. aspx?QueryId=9909\&QueryType=View. Accessed 12 Jun 2011.

2. Kondo K, editor. Kenshō "Kenkō Kakusa Shakai": Kaigo Yobō ni Muketa Shakai Ekigakuteki Daikibo Chōsa. Tokyo: Igaku Shoin; 2007 (In Japanese). Health inequalities in Japan: an empirical study of the older people. Melbourne, VIC: Trans Pacific Press; 2010. (In English).

3. Abe Aya. Kodomo no Kenkō to Hinkon no Keiken. Kaneko Ryuichi: Kōrō Kagaku Kenkyūhi Hojokin (Tōkei Jōhō Sōgō Kenkyū Jigyō, H18-Tōkei-002) Paneru Chōsa (Jūdan Chōsa) ni Kan Suru Sōgōteki Bunseki Shisutemu no Kaihatsu Kenkyū. Heisei 19 Nendo. Sōkatsu Kenkyūhōkokusho. 2008; 205-216.

4. Centers for Disease Control and Prevention. CDC health disparities and inequalities report: United States, 2011. Morb Mortal Wkly Rep. 2011;60:9.

5. Hooper L, et al. Systematic review of long term effects of advice to reduce dietary salt in adults. BMJ. 2002;325:628.

6. Pennant M, et al. Community programs for the prevention of cardiovascular disease: a systematic review. Am J Epidemiol. 2010;172:501-16.

7. Ebrahim S, Taylor F, Ward K, Beswick A, Burke M, Davey Smith G. Multiple risk factor interventions for primary prevention of coronary heart disease. Cochrane Database Syst Rev. 2011; Issue 1. Art. No.: CD001561. https://doi.org/10.1002/14651858.CD001561.pub3

8. WHO. RESOUTIONS WHA62.14 Reducing health inequalities through action on the social determinants of health. Geneva: WHO; 2009. Available at http://apps.who.int/gb/ebwha/pdf_ files/WHA62-REC1/WHA62_REC1-en-P3.pdf.

9. Commission on Social Determinants of Health. Closing the gap in a generation: Health equity through action on the social determinants of health. Geneva: World Health Organisation; 2008. Available at http://whqlibdoc.who.int/publications/2008/9789241563703_eng.pdf.

10. Bonita R, Beaglehole R, Kjellström T. Basic epidemiology 2nd edition. Geneva: World Health Organization; 2006. https://apps.who.int/iris/bitstream/handle/10665/43541/9241547073_ eng.pdf;jsessionid=C9614237B6B47F3B58020677CE986292? sequence=1 
11. World Health Organization (WHO). Adelaide Statement on Health in All Policies: moving towards a shared governance for health and well-being. Report from the International Meeting on Health in All Policies. Geneva: World Health Organization (WHO); 2010. Available at http://www.who.int/social_determinants/hiap_statement_who_sa_final.pdf.

12. Blas E, Kurup AS. Equity, social determinants and public health programmes. Geneva: World Health Organization (WHO); 2010. Available at https://apps.who.int/iris/bitstream/handle/10665/44289/9789241563970_eng.pdf?sequence=1\&isAllowed=y.

13. Kondo K, Rosenberg M, editors. Advancing universal health coverage through knowledge translation for healthy ageing: lessons learnt from the Japan Gerontological Evaluation Study. Geneva: World Health Organization (WHO); 2018. Available at https://apps.who.int/iris/bitstream/handle/10665/279010/9789241514569-eng.pdf.

Open Access This chapter is licensed under the terms of the Creative Commons AttributionNonCommercial-NoDerivatives 4.0 International License (http://creativecommons.org/licenses/ by-nc-nd/4.0/), which permits any noncommercial use, sharing, distribution and reproduction in any medium or format, as long as you give appropriate credit to the original author(s) and the source, provide a link to the Creative Commons licence and indicate if you modified the licensed material. You do not have permission under this licence to share adapted material derived from this chapter or parts of it.

The images or other third party material in this chapter are included in the chapter's Creative Commons licence, unless indicated otherwise in a credit line to the material. If material is not included in the chapter's Creative Commons licence and your intended use is not permitted by statutory regulation or exceeds the permitted use, you will need to obtain permission directly from the copyright holder.

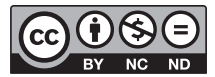

